\title{
Susan C. Bon and Jeffrey C. Sun (Eds.): Law and Education Inequality: Removing Barriers to Educational Opportunities
}

\author{
Charlotte, NC, 2015, 178 pp, ISBN: 978-1-68123-173-0
}

\author{
Hannah Colias ${ }^{1}$
}

Received: 8 November 2016/ Accepted: 10 November 2016/Published online: 14 November 2016

(C) Springer International Publishing 2016

In their edited volume, Law and Education Equality: Removing Barriers to Educational Opportunities, Susan Bon and Jeffery Sun examine how law may hinder desirable education reforms. The authors challenge readers to think about what role policymakers, lawyers, social scientists, and educators could play in altering current courses of action to create a more just educational system. In addition, they identify the current problems that may contribute to educational inequality caused by legislation, regulations, and judicial decisions. Bon and Sun then discuss possible policy alternatives that would bring change to the unequal education system and improve educational standards and practices.

In Chapter 1, Daniel Kiel discusses the paradox seen in educational reform: making education equal for everyone by making it different for everyone. Kiel briefly mentions two theories that were utilized in the educational reform movement of the twenty-first century, which is the reform theory of school choice and the market theory of education. These theories are based on the premise that schools can be improved and opportunity can be made equal if they are different than each other. The families have the option to choose schools with different focuses, such as arts or mathematics. The communities that most commonly embrace this theory are metropolitan, urban areas whose majority of students are minority youth from lower income families. This structure is referred to as the "portfolio model". Schools that embrace the portfolio model vary in many different ways, but they all are founded on three principles: each school has a diverse group of operators,

Hannah Colias

hcolias@indiana.edu

Indiana University Bloomington, Bloomington, IN, USA schools function independently from one another, and the operator's authority depends on the success of the school. The portfolio model distributes power to multiple operators, rather than concentrating the power to a superintendent. The most independent operator in this model is the state-Kiel uses the example of charter schools. These schools are operated by private administrators, who are granted authority based on a contract and governed by the state charter school laws. The multiple operators of these school systems have autonomy and are flexible to test different methods or programs that will target the needs of diverse students. However, due to this autonomy, the district is constantly undergoing evaluations and if there is not a high enough success rate the operator can be terminated. The portfolio is based on the market theory of education, which is founded on the idea that, by creating an incentive for success, the operators will ensure the quality of the education. Therefore, since the model is implemented in lower income areas, it is meant to be an innovative way to create equality and improve the disparities that affect public education. However, this model greatly affects the idea and function of existing public education because it can become more complex and expensive. The operator is autonomous, but still spends money on the same needs as a public school. For example, the operator must find their own vendor for food and negotiate its own contract. Therefore, if there are multiple operators, there will be multiple contracts. This increases the efforts of the operators and can increase the overall costs. This model produces legal issues as well-the laws already in place for public schools are not suitable and require adjustments to reflect the differences in operators. Kiel concludes by questioning if the portfolio model drives equity. The longterm viability of this model is uncertain and will depend on the success of limiting educational barriers. This model 
creates a separation between students and if their operator is less successful than another, their education is unequal and yet still be legally permissible. The competitiveness of the schools would also affect the willingness to share resources necessary to establish a successful system of schools. Therefore, the portfolio model seems to be an underhanded attempt to privatize schools and, if advocates want the model to succeed, it is necessary to improve the model while reducing associated risks.

Chapter 2 Charles Russo and Gerald Cattaro address two parts in the legal and educational issues surrounding religious charter schools. First, the authors examine litigation on state aid to religiously affiliated charter schools and second, they review policies that publicly funded assistance could have an effect on religious missions of nonpublic schools that seek to become faith-based charter schools. The Establishment Clause has caused controversy involving religion and public education. The author discusses the Court's modern Clause perspective on the constitutionality of aid to religiously affiliated entities. The child benefit test, created in 1968, allowed aid if the funds helped the students, rather than the religiously affiliated school. The authors discuss the case Zelman versus Simmons-Harris where the Court upheld a voucher program that helped under privileged students in failing public schools. The Supreme Court decided that this program did not advance religion and deemed it constitutional as an attempt to provide greater educational opportunities for students that were from failing schools. Leaders in the faith-based nonpublic schools fight the economic issues of social secularism, shifts in demographics, increased costs, and financial issues. The changing demographic is shown through the percentage of non-Catholic students enrolling in Catholic schools. This creates a challenge in faith-based schools because they must offer an affordable, high quality education while staying faithful to their religious missions. The authors believe that charter schools are missing the ability to have a faith-based school without teaching about religious faith, which has been driving faith-based nonpublic schools for years. The authors address the argument that charter schools are flexible enough to offer religious objectives in their educational programs. However, it would be an impossible goal for those who serve minority populations in faith-based institutions because they would have to be transformed into "religious schools-lite," schools that incorporate religious themes broadly, which cannot include lessons about their faith if they receive public funding. With the decline of religious nonpublic schools and the rise of faith-based charter schools, there will likely be provisions to current judicial statutes that restrict their ability to operate the schools. However, the author discusses the probability that laws creating religious charter schools will be struck down because they will have difficulty maintaining the requirement to have secular legislative purposes, avoid advancing religion, and concerns with the predicament of religion and government. Other significant concerns lie with the requirement that educational leaders prevent prayer and religious activity from taking place in faith-based charter schools, which are changes that would modify the nature and missions of the schools. Although there are good intentions with supporters, the author concludes that it is unlikely that organizers of faith-based charter schools will succeed.

In Chapter 3 the authors, Carrie Sampson and Sonya Douglass Horsford, discuss the topic of funding equity and improved educational opportunities for English Language Learners. Approximately 1 in 10 children in the public school system speak a language other than English in their homes and are classified as English Language learners (ELL). These students are often treated as a burden to schools and many have been discriminated against. Prior to the Equal Education Opportunities Act of 1974, ELL students were receiving alternative programs through the Bilingual Education Act of 1968. The authors gave an example of Chinese ELL students that were denied resources to receive the same quality of education as nonELL students. These schools then had to obtain guidelines called Lau Remedies that schools to support bilingual measure of teaching and learning. However, in 1981 these remedies were suspended and the ELL programs had to undergo a Castaneda Test. This required that the ELL programs were developed using a theory, have sufficient support, and are assessed based on the program's effectiveness. However, the author argues that the ambiguity of the Castaneda standards leads to variation within programs and therefore deprived ELL students of a quality education. The author provides various examples of legal battles that demonstrate the amount of time it takes to change the ELL programs, which will have negative effects on their education in the meantime. This issue requires immediate action because there has been a large increase of ELL enrollment and decrease in funding for these programs, which affects the educational equity and opportunity. The states have spent over 30 years on standards and accountability of the programs, which demonstrates a major flaw in state-level education policies. They are able to identify a problem, but are incapable of fixing it. Due to the variation of funding levels, mechanisms, and allocations, it makes it very difficult to identify what is necessary to improve student achievement. The authors state that, most importantly, there needs to be a focus on equity in educational policy and state funding. The authors recommend that studies are done to develop funding formulas should include expert opinions to highlight the best ELL practices and specific outcomes. Therefore, policymakers and education leaders should use their demographic and 
educational trends as an opportunity to modernize the states' approach to educating diverse populations. Therefore, more research on the best ways to educate ELL students will improve the nation's equity and success agendas overall.

Chapter 4, Phili Daniel and Jeffrey Sun continue to discuss the law, challenges, and possible solutions in regards to the achievement gap for English Language Learners. According to the Equal Educational Opportunities Act, all public schools must overcome any language barriers that would negatively affect the participation of the students. In this chapter, the author discusses recommendations to close the achievement gap for ELL and suggests an integrative approach, School-University-Policy Practice Model (SUPP Model), where ELL students are supported by integrative services. As mentioned in the previous chapter, ELL students make up about $10 \%$ of public school students and are continuing to grow. To understand the needs of these students, the authors identify the education policies for students and administrators that may affect the achievement gap. The hyper accountability of leaders, mentioned in Chapter 1, may disincentivize good leaders from schools that have high levels of ELL students, which affect the quality of education. Schools must overcome many challenges to ensure that ELL students are receiving an equal education. There is no guidance given by the federal government in implementing these laws and policies, educators must acknowledge that every ELL-student begins at a different level, and administrators are offered a limited amount of resources. First, the authors discuss the issues that accompany a lack of guidance from the federal government. There are no specific policies for ELL programs and there are no guidelines to assess the students. Each of the policies vary from state-to-state and this lack of uniformity results in educational disparities. Secondly, ELL students who start public school are immediately at a disadvantage. Along with learning the same materials as other students, they have a language barrier that negatively affects their educational equity. Accompanying these challenges are the lack of resources provided to ELL programs. Due to the increased enrollment of ELL students, there are not enough teachers who have the training or experience to give them a proper education. Therefore, teachers who are not qualified to teach these students are often in charge, which only solves the short-term issues, while creating long-term negative consequences. These issues require immediate action and the author recommends that policymakers, school administrators, and universities work together to assist with planning, implementing, and evaluating ELL programs in order to close the achievement gap.

Chapter 5 began the third part of the book: students with disabilities. In this chapter the authors, Brenda Kallio,
Richard Geisel, and Angela Jonasson, focused on managing life-threatening allergies in the school setting. The authors begin by discussing the immune reaction to an allergen and symptoms that accompany it. There are various modes of pathways for an allergen to trigger a reaction including, ingestion, touch, and inhalation. If an allergic reaction occurs, a child is allowed to carry their medication in order to reduce the length of time to administer it. However, being that children often lose or misuse their medications, carrying medications is insufficient in protecting all students who have allergies. To remedy this issue, various states permit schools to allow other individuals to administer epinephrine and train all staff on how to administer the medication if necessary. According to the Rehabilitation Act of 1973, Section 504 states that a person must have a physical or mental impairment that substantially limits one or more major life activities. To qualify as a disability, the allergic reaction must be severe. Schools must also be in compliance with the USDA's mandated integrated setting - a student cannot be segregated unnecessarily due to an allergy. Schools are also required to have alternative allergen-free meals upon medical documentation for the allergy. In regards to gathering medical information, the Family Educational Rights and Privacy Act (FERPA) ensures that parents and students have access to their records and that the parent must give consent for a third party $t$ to access these records. In addition, Health Insurance Portability and Accountability Act (HIPPA) protects their health information from any entity. The authors conclude by stating that there are more than three million children with food allergies. Every state has laws that allow students to carry medications and there are laws that provide protection for the child against discrimination.

In Chapter 6 the authors, Susan Bon and Nicole Snyder, discuss individualizing educational opportunities for students with disabilities. The authors begin by discussing the outcomes for students with disabilities after school and the disparities in terms of employment and furthering their education. With the increasing number of children being identified with autism spectrum disorder, it is necessary to create effective transition services that facilitate in obtaining employment and secondary education. The Individuals with Disabilities in Education Act (IDEA) requires local education agencies to provide planning and services for people with disabilities and various revisions have been made over the years. The IDEA now requires that transition planning be in effect when the child is 16 and it must include training, education, employment, and independent living skills. These plans must be updated annually to ensure success. The local education agency (LEA) is required to find ways to meet transition goals in the student's IEP, but they are not required to provide services if the child obtains a regular diploma or exceeds 
age limits. The regulations of the specific components of the student's Summary of Performance (SOP) are state regulated and ambiguous, which leads to a large variation. Therefore, students are left to find their own uncoordinated federal programs that will assist them into the transition into independent living and employment. Several cases have set the guidelines for transition plans including KC Ex Rel. Her Parents versus Nazareth School District. The court stated that the transition plans are not only an academic plan, but related to independent living and employment. In the end, the parents impeded attempts to create an individualized plan and the LEA was not required to include all of their recommendations. The author continues to discuss the standards that courts have been guided by, such as the Rowley standard. This provided the basic level of transition services expected of LEAs. In addition, the courts require that transition standards must be individualized, however geographic diversity results in different standards and expectations for LEAs. As standardized testing becomes more important, the graduation rate of students with disabilities decreases, which seems to be counterproductive in their efforts toward inclusion. Although schools treat the individuals as members of the IEP team, the administrators and parents are often the ones who make accommodations for the students. However, once they reach higher levels of education, the ADA requires that the student is their own advocate. The author then states that the provision of postsecondary disability services is dynamic as a result of judicial intervention that changes the laws and policies. Schools will begin facing a high demand of transitionplanning support and there needs to be resources to accommodate them.

Chapter 7 begins the fourth part of the book and starts the discussion on bullying and LGBT youth. The authors, Geisel, Kallio, and Brodia, begin by discussing the blurred lines between teasing and bullying. Bullying is synonymous with harassment at the federal level in regards to discrimination. The US Department of Education's Office of Civil Rights issued two letters that notified schools about the federal rights violations if they failed to address issues involving bullying or harassment. Bullied victims are protected under the Civil Rights Act of 1964 if the bullying is based on race, nationality, color, sex, and/or disability. There are eleven key components in state bullying laws that are discussed in this chapter, however the authors go on to state that there is no mandate for states to implement the policies and procedures. To understand state bullying legislation, 49 states were analyzed for inclusion based on the components suggested by the federal government. The first component is the Purpose Statement, which encourages schools to be aware of the effects that bullying has, including learning, safety, environment, and engagement. Out of the 49 states analyzed, 42 of them included a Purpose
Statement, which demonstrated that a high percentage of states identify why bullying is inappropriate and can have a negative impact on their students and learning environment. The second component is the Statement of Scope, which addresses the school's jurisdiction. This component includes policies for places where bullying might occur such as activities, transportation to and from school, and the school's technology. The third component is the Specification of Prohibited Conduct. This provides clear definitions about bullying or cyberbullying, which define each of these as intentional efforts to harm an individual, verbal or nonverbal, and is not limited to physical harm. The fourth component is Enumeration of Specific Characteristics-this includes how bullying can be seen in actual or perceived characteristics. Only 19 states enumerate the characteristics of bullying and the remaining 30 do not. Next, the fifth component is the Development and Implementation of LEA Policies. This recommends that LEA policies should be developed and implemented in a state. This recommendation should include administrators, teachers, staff students, parents, law enforcement, and other groups. The high percentage of statutes that require LEAs to include multiple stakeholders in development (91.8\%) demonstrates that bullying is both an educational and community issue. Next, the Components of LEA policies describe the six subcomponents to provide more information about bullying statues. This includes definitions, procedures to report bullying, investigating and responding to bullying, written records, sanctions, and referrals to counseling for the victims. The seventh component is a Review of Local Policies in order to ensure that the state's statutes are met. A Communication Plan is the eighth component, which are established to notify students, parents, and staff members about policies related to bullying. Then, there is a Training and Preventive Education component in place in order to recommend proper training in schools to prevent, identify, and respond to bullying. Transparency and Monitoring make up the tenth component, which suggest LEAs report the percentage of bullying incidents and the school's response to them. However, only 21 state statues have this component. The final component is the Statement of Rights to Other Legal Recourse, which requires LEAs to have a policy statement that does not impede on the victims right to seek legal remedies. The authors conclude by stating that there are no federal laws that address bullying specifically, but victims of bullying can take their case to court using federal antidiscrimination laws. However, these are limited and can only protect the students that are harassed based on race, national origin, color, sex, and/or disability. Therefore, due to the high standards, the authors state that the most efficient relief can be found through the states' statutes.

In Chapter 8, the authors Bellini and Kitchen describe the importance of law and school policies in making 
schools safer for LGBT youth. They begin by stating that LGBT youth are not safe in North American schools and describe that over half of US LGBT students have heard homophobic remarks from staff and $80 \%$ of those students did not see staff intervene. A survey by the Gay. Lesbian, Straight Network (GLSEN) found that over $60 \%$ of LGBT youth stated that they felt unsafe because of the sexual orientation or gender. An alarming $44.1 \%$ of students that reported harassment felt that the response was completely ineffective-this high percentage of harassment has resulted in lower GPAs, depression, truancy, and failure for postsecondary education. Although these statistics are alarming, the authors also state that schools with antibullying/harassment policies and laws provide a safer and more positive school environment. Although Canada is often known to be progressive in their policies and laws, the introduction of rights for LGBT communities is recent. The authors describe various issues in regards to LGBT rights including the issue of religious accommodation. In 2010, the Ministry of Education began to implement a new sex education program, but a publication from LifeSiteNews stated that the program promoted homosexuality and masturbation. This created pressure from Christian Evangelicals and conservative Muslim groups to remove the new sexual education program and parents threatened to remove their children based on "religious accommodation" rights in public schools. There then was a second issue involving students and administrators in the Catholic school system - students argued that Catholic schools must comply with human rights in regards to their sexual orientation. These issues demonstrated the complexity of religious and LGBT rights in the school system. However, according to Bill 13, as long as both schools receive public funding they must comply with the curriculum. A survey to examine the impact of school environment and LGBT inclusion policies was performed. The survey consisted of two parts: the impact of Gay-Straight Alliances (GSA) on school climate and the response of educators to bullying. In this survey $85 \%$ found that the present of GSAs had a positive impact on the school climate. The survey's resultsalso included that students viewed the response of administrators to be more effective and therefore it is important for principals and other officials to demonstrate their support. The authors concluded that the climates of schools are improving with the establishment of GSAs. Legislation that provides policies can lead to an increase in support of the LGBT youth and a safer, educational environment.

Chapter 9 begins the fifth part of the book, Teacher Candidate Dispositions. The authors Kajs, Grigsby, and Divoll discuss the use of disposition criteria in the approval process of teacher candidates by schools of education. The authors begin by describing the expectations that communities have for the school districts to provide high quality educators. The teacher preparation process is made of various components - the first is ensuring that their graduates have beliefs and values that are expected by teaching profession. The authors discuss why disposition criteria are relevant in preparing teachers. They use a brief literature review to assess the criteria and include court cases that address the use of the criteria in the approval/ removal of candidates. The authors then make recommendations for policies, regulations, and practices that support this process. The National Council for Accreditation of Teacher Education (NCATE) merged with the Teacher Education Accreditation Council to form the Council for the Accreditation of Educator Preparation (CAEP), who created new standards on the professional dispositions required of teacher candidates. They require that teachers must "nurture the academic and social development of all students through professional dispositions such as caring, fairness, and the belief that all students can learn." Although clear regulations are in place to help and protect students, teachers, and administrators, there is still a possibility of legal action by a dismissed teacher that can occur. The authors give examples of court cases on disposition criteria in teacher education programs including Reichert versus Elizabethtown College, Winkle versus Ruggieri, and Oyama versus University of Hawaii. These courts upheld the decisions of the colleges and universities to use disposition criteria to assess prospective teachers, but it is possible for there to be future legal issues from candidates that are dismissed based on these standards. Therefore, the authors describe the importance of policies and procedures to address the use of dispositions. Professional dispositions have been shown to have a large impact on the effectiveness on a classroom and according to the examples; the courts typically support the professional judgment of administration's use of disposition criteria.

Chapter 10 concludes the book and discusses dispositional discipline and the challenge to institutional prerogative. The authors Sheeran, Rinaldo, Polka, and Smith begin by describing that the standards of assessing dispositions are not homogenous. They describe dispositional case law and how it related to professional preparation programs. It has been long-standing to assess candidates on the measure of effectiveness and success in the classroom and therefore the school, college, or department of education (SCDE) must create definitions of qualities that they expect of their graduates, develop a method to measure the candidates disposition, and create a program that helps candidates who fall short. Due to the lack of measurement of intangible characteristics of teaching, many evaluations are based on measurable and observable behaviors. However, characteristics there are many intangible characteristics of a teacher that are essential to the success of their 
students including creativity, curiosity, empathy, innovation, and compassion. The authors then review three cases in which courts intervened when teacher education programs did not outline the criteria or follow procedures in removing students preparation programs. The reason for removal was due to falling short in assessing disposition, however the judgment was instinctive rather than factual. The authors then list professional programs such as medicine, dentistry, pharmacy, etc. that have procedures and ways to measure dispositions and conclude that teacher preparation programs may lack these tools. In order to improve teacher preparation programs, evaluators must develop objective measures of disposition, which are clear and legally grounded. To conclude, teachers are expected to educate all students and in order to ensure they are receiving a proper education they must demonstrate knowledge, skills, and dispositions.

Law and Education Inequality expertly examined multiple factors that contribute to inequality in education. Through examining the role of law and how it may negatively impact desirable educational reforms, the authors help readers think critically about how policymakers, lawyers, social scientists, and educators can work toward equal education for all people. By doing so, the study joins other efforts that seek to use empirical understandings of youth and legal responses to their needs to address their rights (see, e.g., Levesque 2015, 2016a, b). This is an emerging field that takes both empirical science and the law seriously. From this perspective, this book makes an invaluable contribution as it provides an example of the importance of this line of work. More specifically, it reveals that, although our society and educational systems in general have come a long way, it is important to recognize that there is inequality in the education system, identify factors that contribute to inequality, and consider ways to remedy them. Through this realization, people can work collaboratively and support the basic liberties of youth from diverse populations.

\section{Compliance with Ethical Standards}

Conflict of interest None.

\section{References}

Levesque, R. J. R. (2015). Adolescence, discrimination, and the law: Addressing dramatic shifts in equality jurisprudence. New York, NY: NYU Press.

Levesque, R. J. R. (Ed.). (2016a). Adolescents, rapid social change, and the law: The transforming nature of protection. New York, NY: Springer.

Levesque, R. J. R. (2016b). Adolescence, privacy and the law: A developmental science perspective. New York: Oxford University Press. 